\title{
RUSSIA'S ARMED FORCES ON THE BRINK OF REFORM
}

Stephen J. Blank

$16-17$

March 16, 1998 